\title{
Mendelian Forms of Human Hypertension and Mechanisms of Disease
}

\author{
Friedrich C. Luft, MD, Franz Volhard Cinic HEIOS Kinikum-Berlin and Max Delbrück Center for Molecular Medicine, \\ Medical Faculty of the Charité, Humboldt University of Berlin, Germany
}

[See related article 271 - 272]

\begin{abstract}
Mendelian forms of hypertension have ushered in a revolution in our knowledge of blood pressure and volume regulation. If we include information on syndromes involving low blood pressure, this knowledge base is doubled. Gucocorticoid remediable aldosteronism, apparent mineralocorticoid excess, and mutations in the mineralocorticoid receptor gene have given us brilliant insights into mineralocorticoid-induced hypertension. The latter discovery has elucidated how mutations may modify the receptor sufficiently to allow erstwhile antagonists to have an agonistic action. The epithelial sodium channel ( $\boxminus \mathrm{NaC}$ ) has been elucidated. Gain-of-function mutations in the $\beta$ and $\gamma$ subunits of $\mathrm{ENaC}$ cause Liddle's syndrome. Loss-of-function mutations in all three subunits of $\mathrm{ENaC}$ cause hypotension (pseudohypoaldosteronism type I). Thus, all three subunits can be mutated, causing either hyper or hypotension. Three loci have been described for Gordon's syndrome, pseudohypoaldosteronism type II. Two members of the WNK serine-threonine kinase family have recently been found to be responsible. Their function has been largely elucidated. Autosomal dominant hypertension with brachydactyly features normal sodium and renin-angiotensin-aldosterone responses. The gene has been mapped to chromosome 12p. The condition is interesting because it may represent a novel neural form of hypertension. Fnally, at least 5 different genes have been described that when mutated can cause pheochromocytoma. Thus, the elucidation of Mendelian blood pressure-regulatory disorders has been a resounding success.
\end{abstract}

RECEIVED: AUGUST 1, 2003

REPRINT REQUESTS:

Friedrich C. Luft, MD

Franz Volhard Clinic

Wiltberg Strasse 50

13125 Berlin, Germany

Telephone: +49 3094172202

Fax: +493094172206

Email: luft@fvk-berlin.de
REVISED AND ACCEPTED: SEPTEMBER 10, 2003

KEYWORDS:

Mendelian hypertension; Aldosteronism; Epithelial sodium channel; Liddle's syndrome; Pseudohypoaldosteronism; Gordon's syndrome;

Brachydactyly; Pheochromocytoma

GRANT SUPPORT:

Studies on autosomal-dominant hypertension and brachydactyly were supported by the Deutsche Forschungsgemeinschaft and by the Helmholtz Foundation. 


\section{GLOSSARY OF TERMS}

Chimeric gene: A gene resulting from a fusion of two gene pieces that became improperly arranged during the crossing over event in the first miotic division. The chimeric gene may have the promoter (regulatory element) of one gene and the coding region of another. Such is the case in GRA (below).

Clathrin-coated pits: Invaginations in the cell membrane where certain receptors or transporters are placed. Examples of this are the low-density lipoprotein cholesterol receptor and the epithelial sodium channel.

Nedd4: Nedd4 belongs to the Hect family of ubiquitin ligases. The protein is involved in the degradation of epithelial sodium channel subunits. If this arrangement does not work, the channel remains in the cell membrane and is "overactive."

Linkage: A technique relying on genetic markers along the genome to find where genes responsible for a given trait are located. A family tree with a given disease or affected sibling pairs are needed. The technique answers the question, "where is it." Thereafter, other methods (positional cloning etc.) are generally necessary to find the responsible gene.

LOD score: Logarithm of the odds ratio. A statistical term relying on a logarithmic expression to delineate how strong the evidence is for linkage of a given trait to a given segment of the genome. A score of 3 is generally considered significant.

YAC, BAC, and PAC: Yeast artificial chromosomes, bacterial artificial chromosomes and plasmid artificial chromosomes. These microorganisms are outfitted with sections of human chromosomal material. They can be cultured to provide however much of the material is needed. They are available commercially. When a gene is mapped by a linkage analysis, investigators commonly span the linkage interval with BACs or PACs so that they can then analyze each smaller interval separately. The Human Genome Project has obviously simplified matters considerably although much still needs to be done.

Haploinsufficiency: Mutations in the heterozygous state, which result in half normal levels of the gene product leading to phenotypic effects, (i.e., are sensitive to gene dosage). If the function of the remaining gene is affected in any way severe disturbances may occur (second hit).

Synteny: Genes or chromosomal regions that show extensive across species homology. The term is generally used comparing sites in the human genome to mouse, rat, or other species.

\section{INTRODUCTION}

Mendelian hypertension is the bright spot in the area of molecular genetics of human hypertension. The opportunity here is that by elucidating rare Mendelian diseases, we shall come to understand mechanisms of disease applicable to primary hypertension. ${ }^{1}$ This promise has been kept largely through the efforts and successes of Lifton and colleagues. ${ }^{2}$ Through their work, we have been introduced to numerous disease mechanisms. Mendelian syndromes are not difficult to diagnose or at least to suspect. The renin-angiotensin system features typical changes in almost every instance (figure 1). In the following report, we will review the syndromes as they stand today.

\section{GLUCOCORTICOID-REMEDIABLE ALDOSTERONISM}

Patients with glucocorticoid-remediable aldosteronism (GRA) have an autosomal dominant hypertension and are usually suspected of having primary aldosteronism. They have a volume expansion, a salt-sensitive form of hypertension, tend to metabolic alkalosis with hypokalemia, and respond to both thiazide diuretics and spironolactone. The latter fact is a clinical clue that mineralocorticoid products may be involved. Their renin values are low while the aldosterone values are elevated. The patients also have 18-hydroxyand 18-oxocortisol, steroids not normally found in urine in large amounts.

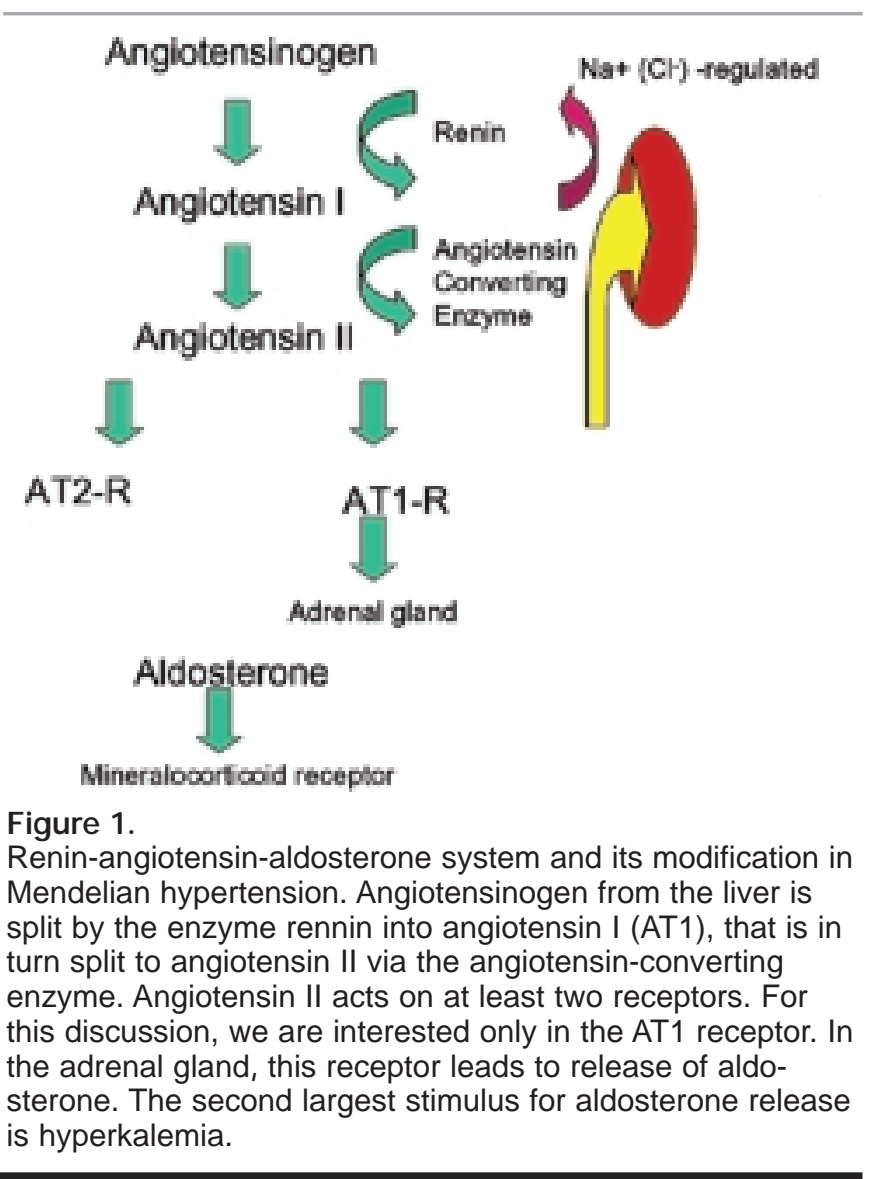


All genetic hypertension clarified to date features low plasma renin activity (PRA) (table 1). If the patient does not have low PRA, forget the diagnosis. In glucocorticoid-remediable aldosteronism (GRA), excess aldosterone (ALD) is made, suppressing PRA. In Liddle's syndrome, the kidney, suppressing PRA and ALD, resorbs excess salt. In apparent mineralocorticoid excess (AME), and in activating mutations of the mineralocorticoid receptor (MR), the same thing is true. In Gordon's syndrome, excess salt is resorbed by the distal tubule lowering PRA, but the patients have hyperkalemia, raising ALD. Patients with autosomal-dominant hypertension with brachydactyly have normal PRA and ALD. The diagnosis can be made with a handshake.

Recognizing these abnormal products (an intermediate phenotype) led to solving the mystery. Replacement quantities of prednisone ameliorate the hypertension, cause the abnormal steroids to disappear, and give the syndrome its name. The abnormal cortisol derivatives and the favorable effects of glucocorticoid treatment suggested that inner cortical zones, which express the gene for $17 \beta$-hydroxylase (CYP17) and are ACTH-responsive, were the source of the excess mineralocorticoids.

Two distinct gene products, $11 \beta$-hydroxylase (CYP11B1) and aldosterone synthase (CYP11B2), perform the terminal steps in glucocorticoid and mineralocorticoid biosynthesis, respectively. A linkage analysis in a large pedigree localized the responsible gene to chromosome 8q, precisely at the site where the genes for $11 \beta$-hydroxylase and aldosterone synthase also reside 3 .

In affected individuals, a chimeric gene consisting of the promotor-regulatory region of $11 \beta$-hydroxylase and the structural portion of aldosterone synthase is located between CYP11B2 and CYP11B1. The chimeric gene results from a miotic mismatch and unequal crossing over (figure 2).

\begin{tabular}{ccc}
\hline Syndrome & $\begin{array}{c}\text { Diagnostic } \\
\text { criteria }\end{array}$ & \\
\hline \multirow{2}{*}{ GRA } & PRA & $\boldsymbol{\nabla}$ \\
Liddle's & ALD & $\boldsymbol{\Delta}$ \\
& PRA & $\boldsymbol{\nabla}$ \\
AME & ALD & $\boldsymbol{\nabla}$ \\
& PRA & $\boldsymbol{\nabla}$ \\
Mineralocorticoid & ALD & $\boldsymbol{\nabla}$ \\
receptor mutations & PRA & $\boldsymbol{\nabla}$ \\
& ALD & $\boldsymbol{\nabla}$ \\
Gordon's syndrome & PRA & $\boldsymbol{\nabla}$ \\
& ALD & $\boldsymbol{\Delta}$
\end{tabular}

Brachydactyly handshake
The protein product performs all reactions required for aldosterone production; however, the protein is ACTH rather than angiotensin (Ang) II-dependent. Ectopic expression of this protein in the inner cortical zones permits the formation of 18-hydroxy- and 18-oxocortisol, the biochemical hallmarks of GRA. Finally, suppressing steroidogenesis in the inner cortical zones with exogenous glucocorticoids alleviates the hypertension.

\section{LIDDLE'S SYNDROME}

Liddle described patients with autosomal dominant Mendelian hypertension who also tended to metabolic alkalosis with hypokalemia. His patients had low renin and low aldosterone values; however, they did not respond to spironolactone, while thiazides and triamterene reduced the blood pressure.

This observation convinced Liddle that they probably did not have a form of mineralocorticoid excess, since a mineralocorticoid receptor blocker did not help them. Liddle reasoned that since their renin activities were low, they must have increased sodium reabsorption of some sort. Liddle speculated that they would show a distal tubular defect of enhanced sodium and chloride reabsorption. A renal transplant performed on a patient with Liddle's syndrome who happened to develop renal failure cured the disease, providing strong evidence that the problem resided within the kidneys rather than in a humoral regulatory system. ${ }^{4}$

Shimkets et al. ${ }^{5}$ subsequently localized the responsible gene of a family with Liddle's syndrome to chromosome 16p and were able to show that the gene encodes for the $\beta$ subunit of the epithelial sodium channel $(\mathrm{ENaC})$. The channel is amiloride and triamterene sensitive, explaining the efficacy of

Chimeric gene with 11- $\mathrm{B} \mathrm{OH}$ promoter and coding region of Aldo synthase

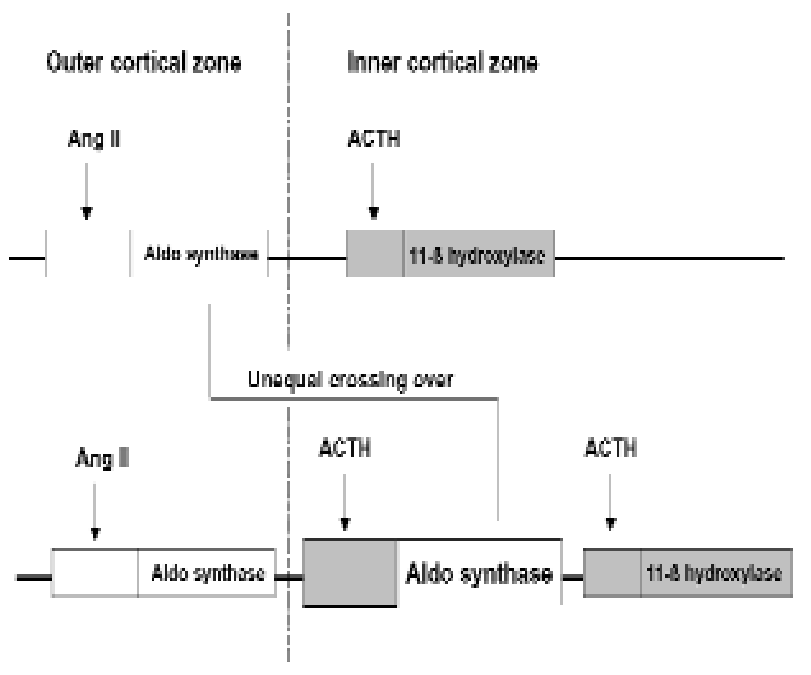

Figure 2. A chimeric gene is formed by miotic mismatch and unequal crossing over with the promoter region of the 11- $\beta$ hydroxylase gene (dark box) and the coding region of the aldosterone synthase gene (white box). As a result, the aldosterone synthase gene is under control of ACTH in the inner cortical zone. (Aldo=Aldosterone, Ang II=Angiotensin II). 
these potassium-sparing diuretics in the syndrome. The channel remains inappropriately permeable (open) even in the face of high salt intake, thereby explaining the salt sensitive hypertension.

Subsequently a mutation in the $\gamma$-subunit of $\mathrm{ENaC}$ has been found, which can also result in Liddle's syndrome. ${ }^{6}$ The molecular mechanisms of Liddle's syndrome involve alteration or deletion in the cytoplasmic tails of the $\beta$ or $\gamma$ subunits. As a consequence, the channels are not internalized (clathrincoated pits pathway) or degraded (Nedd4 pathway), and instead remain activated on the cell surface. ${ }^{7}$

Simply stated, Liddle's patients could not shut off their sodium channels in the distal nephron. When they enjoyed lots of salt on their fries, they absorbed much of it and developed a volume-expansion, low-renin, form of hypertension. Dr. Liddle, a brilliant endocrinologist from Vanderbilt University, figured out what was wrong with his patients long before the discovery of molecular genetics.

\section{APPARENT MINERALOCORTICOID EXCESS}

Genetic apparent mineralocorticoid excess (AME) resembles the syndrome observed in persons ingesting large amounts of licorice. Licorice gluttony and treatment with carbenoxalone both cause a volume expansion, low renin, low aldosterone, salt-sensitive form of hypertension, which may also feature metabolic alkalosis and hypokalemia. Interestingly, the hypertension responds to both thiazide and spironolactone, but no abnormal steroid products are present in the urine. Both licorice and carbenoxolone contain glycyrrhetinic acid, which was found to inhibit the enzyme $11 \beta$-hydroxysteroid dehydrogenase.

$11 \beta$-hydroxysteroid dehydrogenase is responsible for converting cortisol to cortisone. In the distal renal tubule, this step is crucial for protecting the mineralocorticoid receptor, which has the same affinity for cortisol as it does for aldosterone. This step protects us all from developing AME. Inhibition of $11 \beta$-hydroxysteroid dehydrogenase results in AME. Interestingly, AME may also occur as a rare, autosomal recessive form of hypertension.

Needless to say, the $11 \beta$-hydroxysteroid dehydrogenase gene, which has a renal-specific renal isoform, was a hot candidate gene for this condition. The clinical clues helpful in resolving this condition were: (1) volume dependent salt sensitive hypertension, (2) tendency to hypokalemia and metabolic alkalosis, (3) low renin and low aldosterone values, (4) responsiveness to both thiazides and spironolactone despite absence of aldosterone or any abnormal mineralocorticoid products, (5) and resemblance to licorice gluttony.

Mune et al. ${ }^{8}$ solved the mystery. In 8 of 9 families, mutations in the renal-specific isoform gene for $11 \beta$-hydroxysteroid dehydrogenase were found which indeed rendered the pro- duct incapable of converting cortisol to cortisone (figure 3). Thus, the mineralocorticoid receptor is unprotected from cortisol in these patients and cortisol functions to occupy the mineralocorticoid receptor.

The fascinating possibility that AME might be relevant in the heterozygous state has been raised by Li et al., ${ }^{9}$ who observed a patient with apparent mineralocorticoid hypertension at age 38 years, who had a daughter with homozygous AME. The patient had low renin and aldosterone concentrations and was found to have a mutation in the gene for 11 $\beta$-hydroxysteroid dehydrogenase.

\section{MINERALOCORTICOID RECEPTOR}

The Lifton group recently presented a new Mendelian form of hypertension caused by an activating mutation in the mineralocorticoid receptor. ${ }^{10}$ The investigators screened for mutations in the mineralocorticoid receptor in seven unrelated patients referred for possible monogenic hypertension with the single-strand conformation polymorphism technique. One patient had a heterozygous mutation at codon 810 in the mineralocorticoid receptor gene, resulting in a leucine for serine substitution. This residue lies in the hormone-binding domain. The patient's kindred was carefully examined.

The index case had severe hypertension, as did 4 relatives. Four other relatives had no hypertension. Affected persons all exhibited the leucine for serine substitutions, had low plasma renin activities, and low aldosterone concentrations. Since the phenotype resembles Liddle's syndrome, the investigators ruled out the presence of $\mathrm{ENaC}$ mutations.

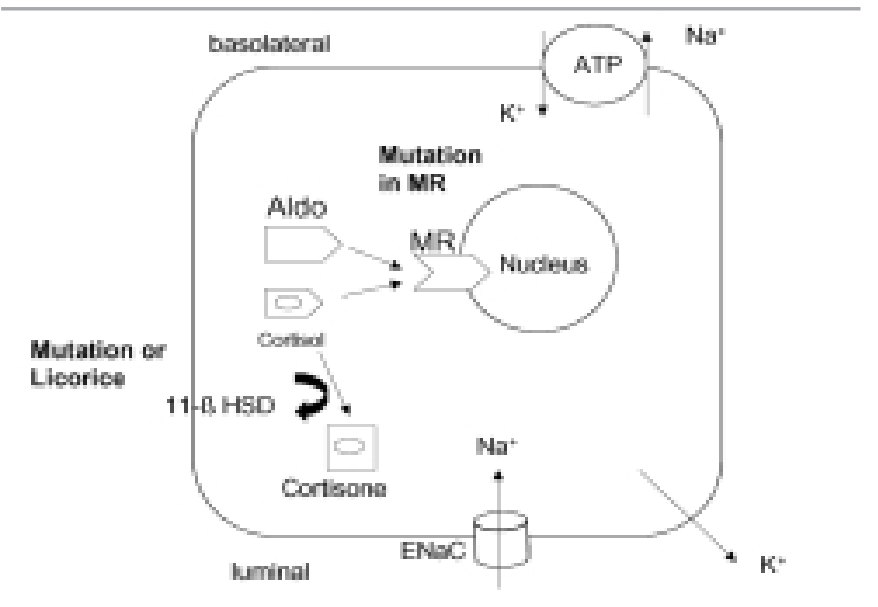

Figure 3. The diagram shows a cortical collecting duct cell. The mineralocorticoid receptor (MR) has the same affinity for cortisol as for aldosterone (Aldo). The enzyme 11- $\beta$ hydroxysteroid dehydrogenase (11- $\beta$ HSD) "protects" the MR by metabolizing cortisol to cortisone, which has no affinity. A mutated or an inhibited enzyme results in an increased intracellular concentration of cortisol and an increased activation of the MR. A mutated MR can result in an altered configuration so that the MR is activated by sterols not containing a 21-hydroxyl group. Increased MR activity causes enhanced $\mathrm{Na}+$ reabsorption (ENaC, Na-K-ATPase) and $\mathrm{K}+$ excretion. 
The authors speculate that the mineralocorticoid receptor gene mutation is an activating mutation in the receptor. Interestingly, affected women exhibit a worsening of hypertension during pregnancy, suggesting that progesterone occupancy of the receptor results in activation rather than inhibition of aldosterone-like effects. Similarly, spironolactone makes the blood pressure elevation worse, rather than better.

Geller et al. ${ }^{10}$ were successful in elucidating the mechanism of the mutation. Their work is a wonderful example of a successful cooperation between molecular genetics and structural proteomics. The MR-S810L mutation allows mineralocorticoid receptor activation by steroids lacking 21-hydroxyl groups. The L810 residue in helix 5 of the ligand-binding domain makes a new van der Waals interaction with A773 in helix 3. This interaction eliminates the requirement for the 21-hydroxyl group of aldosterone to interact with N770 in helix 3. The modification explains why compounds that are normally antagonists now are agonists for the receptor.

Clinicians will not need to concern themselves with Van der Waals forces. Suffice it to say, the mineralocorticoid receptor in these patients has an abnormal shape so that it can be activated by progesterone and by spironolactone, compounds that generally block this receptor. Worse than that, the receptor runs at $25 \%$ function even when not occupied by any ligand.

\section{PSEUDOHYPOALDOSTERONISM TYPE II}

PHA type II (Gordon's syndrome) is characterized by familial hypertension with hyperkalemia, slight hyperchloremic metabolic acidosis, and otherwise normal renal function. Thiazide diuretics are highly effective in this syndrome, commensurate with salt sensitivity. A multilocus linkage analysis ${ }^{11}$ yielded a lod score of 8.1 for linkage to chromosomes $1 \mathrm{q}$ and $17 \mathrm{p}$. Interestingly, the chromosome $17 \mathrm{p}$ locus overlaps a syntenic interval in the rat that contains a blood pressure quantitative trait locus.

PHA type II provides promise in leading to cloning of two additional as yet not appreciated genes leading to hypertension. Disse-Nicodeme et al. ${ }^{12}$ described a new locus on chromosome 12p13. They analyzed a large French family, in which 12 affected members over three generations confirmed the autosomal dominant inheritance. Affected subjects had hypertension together with long-term hyperkalemia, hyperchloremia, normal plasma creatinine, and low renin levels.

Wilson et al. unraveled the puzzle. ${ }^{13}$ They identified two genes causing pseudohypoaldosteronism type II. Both genes encode members of the WNK family of serine-threonine kinases. Disease-causing mutations in WNK1 are large intronic deletions that increase WNK1 expression. The mutations in WNK4 are missense and cause a loss of function. The mutations cluster in a short, highly conserved segment of the encoded protein. Both proteins are expressed in the distal nephron. WNK1 is cytoplasmic, while WNK4 localizes to tight junctions.

Recent work by Yang et al. ${ }^{14}$ used the Xenopus oocyte system to show that WNK4 suppresses the thiazide-sensitive sodium chloride cotransporter. However, WNK4 does not interfere with cotransporter protein synthesis. Instead, the cotransporter is not incorporated into the cell membrane and cannot come to the surface. Wilson et al. ${ }^{15}$ have presented similar findings. WNK1 expression, on the other hand, prevents the WNK4 suppression of the cotransporter. Thus, the WNK kinases serve as a sodium regulatory pathway in the distal nephron (figure 4). A gain of function mutation in WNK1 would result in highly active cotransporter function. A loss of function mutation in WNK4 would have the same effect.

PHA type II is the mirror image of Gitelman's syndrome, a condition characterized by volume contraction, metabolic alkalosis, and hypokalemia. ${ }^{2}$ In Gitelman's syndrome, the cotransporter is mutated and cannot function properly. PHA type II and Gitelman's syndrome provide a great opportunity to elucidate electrolyte handling via the cotransporter in the distal tubule and cortical collecting duct.

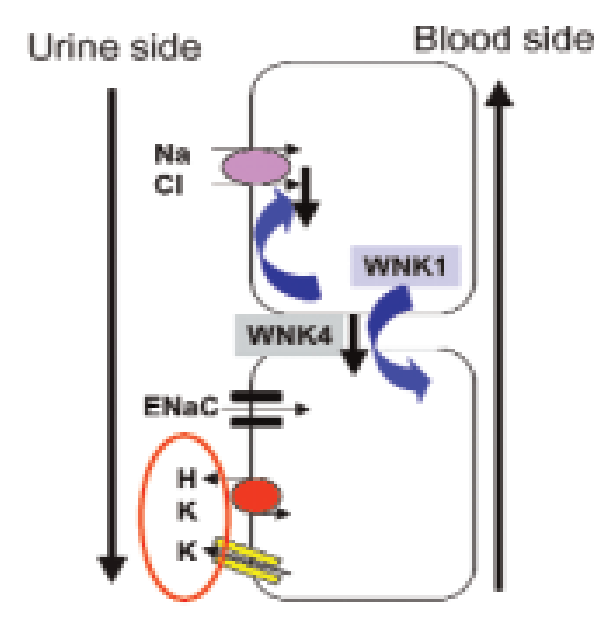

Figure 4. Shown is the distal nephron. The thiazide-sensitive $\mathrm{Na}, \mathrm{Cl}$ cotransporter is over-active in pseudohypoaldosteronism type 2. As a result, less $\mathrm{Na}$ is available for the $\mathrm{ENaC}$ and less $\mathrm{K}$ and $\mathrm{H}$ ions are excreted in the cortical collecting duct. Therefore, the syndrome features volume expansion, hypertension, hyperkalemia and mild hyperchloremic metabolic acidosis. "With-no-lysine" (WNK) kinase 4 down-regulates the cotransporter. When the kinase is mutated, the cotransporter is hyperactive. WNK1 regulates WNK4 downward. Gain-of-function mutations in WNK1, would downregulate WNK4, causing cotransporter hyperactivity. 


\section{AUTOSOMAL DOMINANT HYPERTENSION WITH BRACHYDACTYLY}

Bilginturan et al. first described this form of Mendelian hypertension in 1974. ${ }^{16}$ Affected family members, who feature brachydactyly type E (figure 5), have a dramatic increase in blood pressure with age, and die before the age of 50 years from stroke.

The Turkish family was re-examined in $1994 .{ }^{17}$ The hypertension can be easily distinguished from other monogenic hypertensive syndromes described thus far. The patients are not salt-sensitive and have normal renin, angiotensin, aldosterone and catecholamine responses. By measuring plasma renin activity and plasma aldosterone supine and upright, other conditions can be conveniently excluded. ${ }^{18}$ In glucocorticoid remediable aldosteronism, PRA should be low while aldosterone concentrations are on the high normal side. In Liddle's syndrome, apparent mineralocorticoid excess, pseudohypoaldosteronism type II, and mutations in the mineralocorticoid receptor, PRA and aldosterone levels should both be low. However, in autosomal dominant hypertension with brachydactyly, PRA and aldosterone values are normal.

The phenotyping efforts also showed that the patients do not respond to any particular form of medication. ${ }^{19} \mathrm{~A}$ beta-blocker, calcium antagonists, alpha-blocker and ACE inhibitor all improved blood pressure without significant difference. A multi-drug therapy is required for the treatment of patients.

The mechanism of the hypertension is unknown. However, an additional phenotype was discovered, which may provide a clue. Intra-operative observations ${ }^{20,21}$ anatomical studies, ${ }^{22}$ and magnetic resonance imaging (MRI) ${ }^{23}$ have demonstrated a posterior fossa neurovascular contact anomaly in patients with essential hypertension. this anomaly is believed to represent neurovascular compression (NVC) of the ventrolateral medulla (VLM) at the root entry zone of cranial nerves IX and $\mathrm{X}$

The NVC, which is generally observed on the left side in essential hypertension, consists of a looping vessel, which attaches to the root entry zones of the cranial nerves. The NVC may result in a hyperactive dysfunction of the respective underlying structure. In patients with hypertension, NVC is predominately caused by a posterior inferior cerebellar artery (PICA) loop.

Due to Bilginturan's unpublished initial observation concerning looping vessels in one patient upon cerebral angiography and our earlier findings, we performed MRI in 27 family members. All 15 affected persons had evidence for NVC. All had left sided PICA or vertebral artery loops, while 6 had bilateral NVC. None of the nonaffected family members had NVC. These MRI data are highly significant and suggested NVC at the left VLM as an intermediate phenotype of this syndrome. ${ }^{24}$ Based on these results detailed autonomic testing was performed. ${ }^{25}$
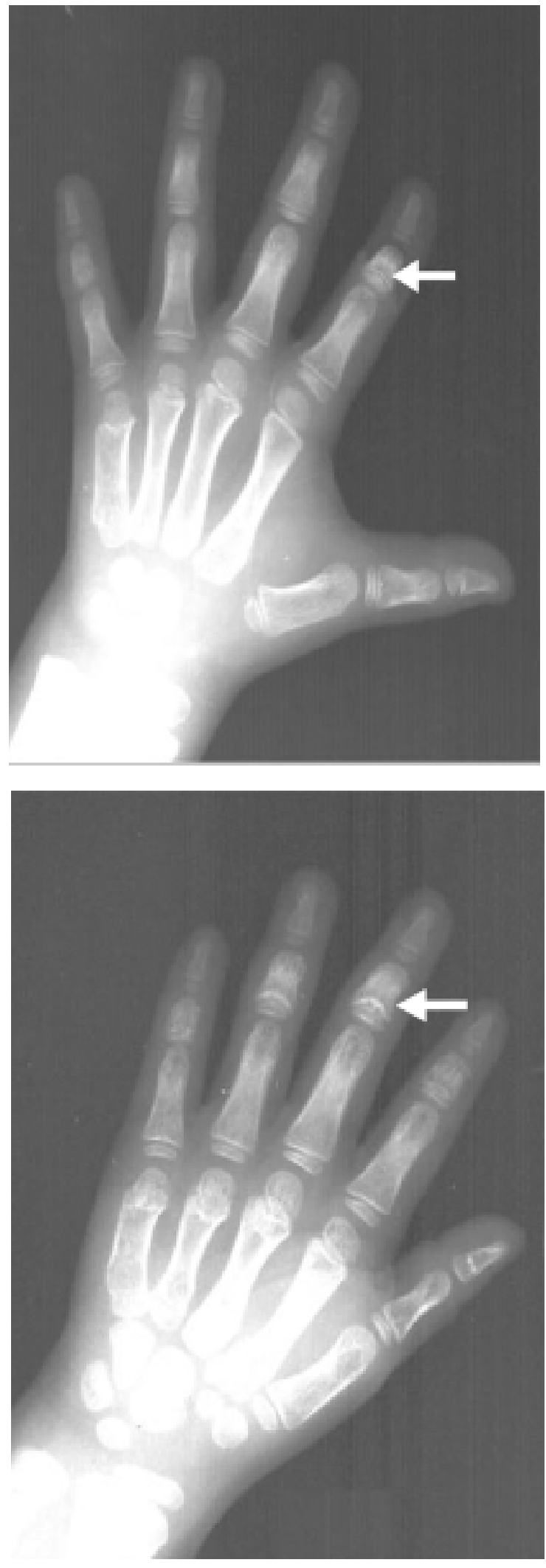

Figure 5. Hand roentgenogram of a 6 year-old Turkish boy with autosomal dominant hypertension (blood pressure $150 / 90 \mathrm{~mm} \mathrm{Hg}$ ) and brachydactyly type $\mathrm{E}$ is shown. The white arrow indicates the shortened metacarpal bones, which define this form of brachydactyly. The phalanges are also shortened. Additionally, cone shaped epiphyses are present (marked by white arrow). 
In young patients with Mendelian hypertension, the hypothesis was tested whether or not the hypertension was mediated through sympathetic activation and if changes in increased sympathetic nerve traffic, vascular sensitivity, or impaired baroreflex buffering would contribute to the phenotype. Blood pressure during complete ganglionic blockade with trimethaphan was 139/82 mm Hg and 90/50 $\mathrm{mm} \mathrm{Hg}$ in patients and in controls, respectively. However, sympathetic stimuli like cold pressor, handgrip testing, and upright posture all increased blood pressure excessively. In contrast, muscle sympathetic nerve activity (tested by microneurography) was not increased at rest or during cold pressor test. The dose of the alpha agonist phenylephrine that increased systolic blood pressure $12.5 \mathrm{~mm} \mathrm{Hg}$ was $8 \mu \mathrm{g}$ in patients and $135 \mu \mathrm{g}$ in control subjects before ganglionic blockade and $5 \mu \mathrm{g}$ in patients and $13 \mu \mathrm{g}$ in control subjects during ganglionic blockade (figure 6). Patients reacted with 17-fold increased sensitivity to phenylephrine at baseline compared to controls. During ganglionic blockade (baroreceptor reflex blocked) this difference was diminished to 2.6-fold.

These results suggest that in patients with monogenic hypertension and radiological evidence of NVC of the VLM, basal blood pressure is increased independent of autonomic activity. However, sympathetic stimuli cause an excessive increase in blood pressure. Increased sympathetic nerve traffic or increased vascular sensitivity cannot explain this excessive response. A possible explanation would be that the

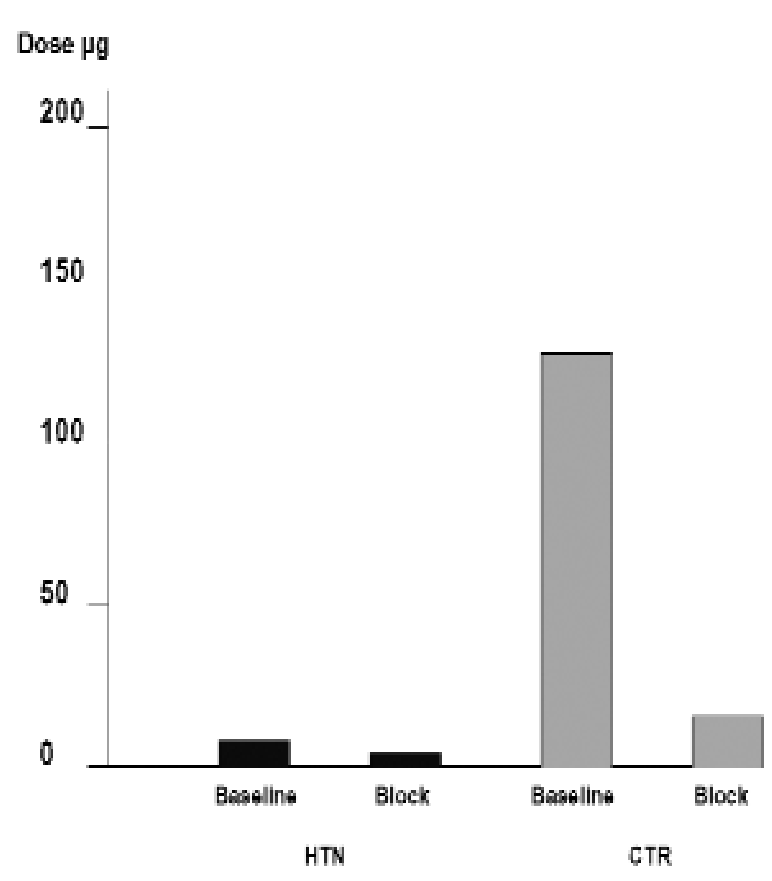

Figure 6. Doses of phenylephrine, which increase blood pressure $12.5 \mathrm{~mm} \mathrm{Hg}$ before and during ganglion blockade with trimethaphan. The sensitivity to the alpha-agonist phenylephrine at baseline is in patients (HTN, black symbols) significantly higher compared to controls (CTR). After interruption of the baroreflex during ganglion blockade this difference is markedly diminished. ability of the baroreflex to buffer changes in vascular tone is severely impaired. The hypertension could be related to abnormal baroreceptor reflex function in these subjects.

A genome wide screen was performed to identify the responsible gene(s). The gene was mapped 26 to the short arm of chromosome 12. Additional families with the same syndrome and a chromosome $12 \mathrm{p}$ deletion syndrome in a Japanese child narrowed down the critical area of interest. ${ }^{27,28} \mathrm{~A}$ family with a similar phenotype including type E brachydactyly but without hypertension was identified. The gene locus did not map to chromosome $12 \mathrm{p}$, indicating the presence of multiple brachydactyly type E loci (unpublished data). Several candidate genes within the area of interest have been sequenced so far without success. One example is the gene for parathyroid hormone related peptide (PTHrP), which was considered a highly attractive candidate, since the PTHrP-homozygous gene-disrupted mouse has skeletal anomalies. $^{29}$

An excellent candidate gene for the short-stature, brachydactyly phenotype was L-SOX5, a transcription factor that regulates collagen I synthesis during development and is expressed in the digits. This gene was eliminated with single nucleotide polymorphism linkage disequilibrium mapping (unpublished).

Mendelian syndromes offer clear insight into mechanisms of disease. However, their general relevance to complex genetic disease is not invariable. Our associates performed family studies in China and identified large kindreds in Shijingshan province, a relatively isolated area. The rationale behind studying relatively isolated population is the belief that fewer genes might be responsible for complex genetic traits in such isolated societies.

The hypertension in these Chinese kindreds was carefully studied. Secondary causes of hypertension were specifically excluded. The renin and aldosterone responses were not suggestive of known Mendelian conditions. A total genome scan was conducted in these families and the hypertensive trait was linked to chromosome $12 \mathrm{p}$ with a significant lod score $>3.0 .30$

Concordance with our locus is excellent. These findings, coupled with an earlier observation from an identical-bydescent sib-pair linkage study of dizygotic twins and their parents from our laboratory, ${ }^{31}$ provide strong evidence for more generalized importance of the chromosome $12 p$ locus to blood pressure regulation and essential hypertension. The primary candidate genes in the region are those encoding phosphodiesterase 3, an ATP-dependent potassium channel Kir6.1, and the sulfonylurea receptor 2.

Since the screening for mutations in candidate genes did not reveal any positive findings we performed cytogenetic studies to screen for possible chromosomal rearrangements in the linked segment. The link between cytogenetics and 
Mendelism has received major impetus with the advent of techniques such as interphase fluorescent in situ hybridization (FISH).

High-resolution chromosome analysis, molecular cytogenetics, and study of the association between specific chromosome rearrangements and single gene disorders have provided a chromosomal basis for a number of Mendelian diseases. ${ }^{32}$ Deletions and duplications of small regions, usually less than $3 \mathrm{Mb}$ in size, result in an alteration of normal gene dosage of a number of unrelated genes physically close to each other and are responsible for contiguous gene syndromes. For example, haploinsufficiency is implicated for del 8q24.1 in Langer-Giedion syndrome, del 17p13.3 in Miller-Dieker syndrome, and del 22q11.2 in DiGeorge and velocardiofacial syndromes. ${ }^{32}$

Another chromosomal mechanism causing Mendelian phenotypes is translocation, which may eventually interrupt a disease gene. Translocation breakpoints are running through a relevant gene, hindering the production of the gene product. Examples include the Rubinstein-Taybi syndrome.

We were intrigued by a recent report in which aromatase, the key enzyme for estrogen biosynthesis in males exhibited markedly increased function resulting in severe gynecomastia in a father and son, as well as in a third unrelated person. ${ }^{33}$ The investigators reasoned that in their patients, the aromatase gene might not be located behind its usual promoter and could be driven by something else.

With interphase FISH using bacterial artificial chromosome (BAC) probes, they found that inversion rearrangement mutations had occurred in the three affected persons. In these patients, the aromatase gene was outfitted with promoters normally belonging to other genes. These promoters activated the aromatase gene continuously. The mutations probably gave rise to the overexpression of aromatase in the brain and thus to increased local estrogen production.

We believe that a rearrangement could be responsible for our syndrome. First, the diversity of the phenotypes raises the possibility of a contiguous gene syndrome involving perhaps L-SOX5 and other genes in the region. The candidates, such as PDE3 may be exhibiting gain of function. To test this hypothesis, we are preparing BAC probes for interphase FISH. Concomitantly, we will have to test our candidate genes, namely PDE3, Kir6.1, and the sulfonylurea receptor 2 .

We envision physiological studies at the systemic and local levels, including forearm blood flow studies. Milrinone, diazoxide, and glibenclamide may serve as pharmacological probes. Buttocks biopsies will be necessary to study mRNA expression of the candidates including a survey of the $5^{\prime}$ untranslated region. Finally, physiological studies of isolated blood vessels are foreseen.

\section{PHEOCHROMOCYTOMA SYNDROMES}

Numerous Mendelian pheochromocytoma syndromes are known. The conditions are not rare and the textbooks should be revised. Every patient with pheochromocytoma should be considered as having one of these syndromes until proven otherwise. ${ }^{34}$

Multiple endocrine neoplasia type 2 is characterized by medullary carcinoma of the thyroid, pheochromocytoma, and hyperparathyroidism. Developmental anomalies may also occur. The disease is caused by mutations in the RET proto-oncogene that resides on chromosome 10 . The pheochromocytomas occur exclusively in the adrenal glands.

Von Hippel-Lindau disease is typically associated with retinal angiomas, hemangioblastomas in the central nervous system, clear cell renal cancer, and pheochromocytoma. The VHL gene is located on chromosome 3 and serves as a tumor suppressor. The pheochromocytomas may occur in the adrenal gland, paraganglia and in the thorax. About $1 \%$ of patients with neurofibromatosis type 1 develop pheochromocytoma. The NF 1 gene is located on chromosome 17. The pheochromocytoma-paraganglioma syndromes have recently been elucidated. Mutations in various succinate dehydrogenase subunits have been found to be responsible.

The textbooks teach us that about $10 \%$ of patients with pheochromocytoma have their tumors because of some genetic syndrome. In this case, the textbooks are probably incorrect. According to a recent report, about $30 \%$ of patients with pheochromocytoma had a genetic syndrome. In any event, a family history is a good idea.

\section{SUMMARY}

In this brief commentary, we have focused on Mendelian forms of hypertension. However, much is also to be learned from Mendelian causes of hypotension.

Lifton and colleagues (reviewed in 2) have elucidated mutations in the ENaC alpha subunit causing pseudohypoaldosteronism type I, three mutations involving transporters in the loop of Henle causing Bartter's syndrome, and mutations in the sodium chloride cotransporter causing Gitelman's syndrome. These conditions also speak to the issue of hypertension because they address problems in sodium handling, volume homeostasis and blood pressure regulation. Similarly, a mutation in the norepinephrine transporter has been described causing orthostatic hypotension, tachycardia, and syncope. ${ }^{35}$

The lessons learned from these Mendelian syndromes has been profound, a genetically driven revolution in our knowledge. 


\section{REFERENCES}

1. Luft FC, Schuster H, Bilginturan N, Wienker T. "Treasure your exceptions": what we can learn from autosomal-dominant inherited forms of hypertension. J Hypertens 1995;13:15351538.

2. Lifton RP, Gharavi AG, Geller DS. Molecular mechanisms of human hypertension. Cell 2001;104:545-556.

3. Lifton RP, Dluhy RG, Powers M, Rich GM, Cook S, Ulick S, Lalouel JM. A chimaeric 11ß-hydroxylase/aldosterone synthase gene causes glucocorticoid-remediable aldosteronism and human hypertension. Nature 1992;355:262-265.

4 . Botero-Velez M, Curtis JJ, Warnock DG. Brief report: Liddle's syndrome revisited--a disorder of sodium reabsorption in the distal tubule. N Engl J Med 1994;330:178-181.

5 . Shimkets RA, Warnock DG, Bositis CM, Nelson-Williams C, Hansson JH, Schambelan M, Gill JR Jr, Ulick S, Milora RV, Findling JW, Canessa CM, Rossier BC, Lifton RP. Liddle's syndrome: Heritable human hypertension caused by mutations in the $\beta$ subunit of the epithelial sodium channel. Cell 1994;79:407-414.

6. Hansson JH, Nelson-Williams C, Suzuki H, Schild L, Shimkets R, Lu Y, Canessa C, Iwasaki T, Rossier B, Lifton RP. Hypertension caused by a truncated epithelial sodium channel _ subunit: genetic heterogeneity of Liddle syndrome. Nat Genet 1995; 11:76-82.

7. Palmer BF, Alpern RJ. Liddle's syndrome. Am J Med 1998;104:301-309.

8. Mune T, Rogerson FM, Nikkilä H, Agarwal AK, White PC. Human hypertension caused by mutations in the kidney isozyme of 11 ß-hydroxysteroid dehydrogenase. Nat Genet 1995;10:394-399.

9. Li A, Li KX, Marui S, Krozowski ZS, Batista MC, Whorwood CB, Arnhold IJ, Shackleton CH, Mendonca BB, Stewart PM: Apparent mineralocorticoid excess in a Brazilian kindred: hypertension in the heterozygous state. J Hypertens 1997; $15: 1397-1402$.

10. Geller DS, Farhi A, Pinkerton N, Fradley M, Moritz M, Spitzer A, Meinke G, Tsai FT, Sigler PB, Lifton RP. Activating mineralocorticoid receptor mutation in hypertension exacerbated by pregnancy. Science 2000;289:119-123.

11. Mansfield TA, Simon DB, Farfel Z, Bia M, Tucci JR, Lebel M, Gutkin M, Vialettes B, Christofilis MA, Kauppinen-Makelin R, Mayan H, Risch N, Lifton RP. Multilocus linkage of familial hyperkalaemia and hypertension, pseudohypoaldosteronism type II, to chromosomes 1q31-42 and 17p11-q21. Nat Genet 1997;16:202-205.

12. Disse-Nicodeme S, Achard JM, Desitter I, Houot AM, Fournier A, Corvol P, Jeunemaitre X. A new locus on chromosome 12 p13.3 for pseudohypoaldosteronism type II, an autosomal dominant form of hypertension. Am J Hum Genet 2000;67:302-310.

13. Wilson FH, Disse-Nicodeme S, Choate KA, Ishikawa K, Nelson-Williams C, Disitter I, Gunel M, Milford DV, Lipkin GW, Achard JM, Feely MP, Dussol B, Berland Y, Unwin RJ, Mayan H, Simon DB, Farfel Z, Jeunemaitre X, Lifton RP. Human hypertension caused by mutations in WNK kinases. Science 2001;293:1107-1112.

14. Yang CL, Angell J, Mitchell R, Ellison DH. WNK kinases regulate thiazide-sensitive $\mathrm{Na}-\mathrm{Cl}$ cotransport. J Clin Invest 2003;111:1039-1045.

15. Wilson FH, Kahle KT, Sabath E, Lalioti MD, Rapson AK, Hoover RS, Hebert SC, Gamba G, Lifton RP. Molecular pathogenesis of inherited hypertension with hyperkalemia: the $\mathrm{Na}-\mathrm{Cl}$ cotransporter is inhibited by wildtype but not mutant WNK4. Proc Natl Acad Sci U S A 2003;100:680-684
16. Bilginturan N, Zileli S, Karacadag S, Pirnar T. Hereditary brachydactyly associated with hypertension. J Med Genet 1973;10:253-259.

17. Schuster H, Wienker TF, Toka HR, Bähring S, Jeschke E, Toka O, Busjahn A, Hempel A, Tahlhammer C, Oelkers W, Kunze J, Bilginturan N, Haller H, Luft FC. Autosomal dominant hypertension and brachydactyly in a Turkish kindred resembles essential hypertension. Hypertension 1996;28:1085-1092.

18. Weinberger MH, Fineberg NS. The diagnosis of primary aldosteronism and separation of two major subtypes. Arch Intern Med 1993;153:2125-2129.

19. Schuster H, Toka O, Toka HR, Busjahn A, Öztekin Ö, Wienker TF, Bilginturan N, Bähring S, Skrabal F, Haller H, Luft FC. A cross-over medication trial for autosomal-dominant hypertension with brachydactyly. Kidney Int 1998;53:167172.

20. Jannetta PJ, Segal R, Wolfson SK Jr. Neurogenic hypertension: etiology and surgical treatment. I. Observations in 53 patients. Ann Surg 1985;201:391-398.

21. Fein JM, Frishman W. Neurogenic hypertension related to vascular compression of the lateral medulla. Neurosurgery 1980;6:615-622.

22. Naraghi R, Gaab MR, Walter GF, Kleineberg B. Arterial hypertension and neurovascular compression at the ventrolateral medulla.: A comparative microanatomical and pathological study. J Neurosurg 1992;77:103-112.

23. Naraghi R, Geiger H, Crnac J, Huk W, Fahlbusch R, Engels G, Luft FC. Posterior fossa neurovascular anomalies in essential hypertension. Lancet 1994;344:1466-1470.

24. Naraghi R, Schuster H, Toka HR, Bahring S, Toka O, Oztekin $\mathrm{O}$, Bilginturan N, Knoblauch H, Wienker TF, Busjahn A, Haller H, Fahlbusch R, Luft FC. Neurovascular compression at the ventrolateral medulla in autosomal dominant hypertension and brachydactyly. Stroke 1997;28:1749-1754.

25. Jordan J, Toka HR, Heusser K, Toka O, Shannon JR, Tank J, Diedrich A, Stabroth C, Stoffels M, Naraghi R, Oelkers W, Schuster H, Schobel HP, Haller H, Luft FC. Severely impaired baroreflex buffering in patients with monogenic hypertension and neurovascular contact. Circulation 2000;102:2611-2618.

26. Schuster H, Wienker TE, Bähring S, Bilginturan N, Toka HR, Neitzel H, Jeschke E, Toka O, Gilbert D, Lowe A, Ott J, Haller H, Luft FC. Severe autosomal dominant hypertension and brachydactyly in a unique Turkish kindred maps to human chromosome 12. Nat Genet 1996;13:98-100.

27. Toka HR, Bähring S, Chitayat D, Melby JC, Whitehead R, Jeschke E, Wienker TF, Toka O, Schuster H, Luft FC. Families with autosomal-dominant brachydactyly type E, short stature, and severe hypertension. Ann Intern Med 1998;129:204-208.

28. Bähring S, Nagai T, Toka HR, Nitz I, Toka O, Aydin A, Muhl A, Wienker TF, Schuster H, Luft FC. Deletion at 12p in a Japanese child with brachydactyly overlaps the assigned locus of brachydactyly with hypertension in a Turkish family. Am J Hum Genet 1997;60:732-735.

29. Karaplis AC, Luz A, Glowacki J, Bronson RT, Tybulewicz VL, Kronenberg HM, Mulligan RC. Lethal skeletal dysplasia from targeted disruption of the parathyroid hormone-related peptide gene. Genes Dev 1994;8:277-289.

30. Gong M, Zhang H, Schulz H, Lee YA, Sun K, Bähring S, Luft FC, Nürnberg P, Reis A, Rohde K, Ganten D, Hui R and Hübner N. Genome-wide linkage reveals a locus for human essential (primary) hypertension on chromosome 12p. Hum Mol Genet 2003;12:1273-1277. 
31. Nagy Z, Busjahn A, Bahring S, Faulhaber HD, Gohlke HR, Knoblauch H, Rosenthal M, Muller-Myhsok B, Schuster H and Luft FC. Quantitative trait loci for blood pressure exist near the IGF-1, the Liddle syndrome, the angiotensin IIreceptor gene and the renin loci in man. J Am Soc Nephrol 1999;10:1709-1716.

32. Dallapiccola B, Mingarelli R, Novelli G. The link between cytogenetics and Mendelism. Biomed Pharmacother 1995;49:83-93.

33. Shozu M, Sebastian S, Takayama K, Hsu WT, Schultz RA, Neely K, Bryant M, and Bulun SE. Estrogen excess associated with novel gain-of-function mutations affecting the aromatase gene. N Engl J Med 2003;348:1855-1865.

34. Neumann HP, Bausch B, McWhinney SR, Bender BU, Gimm O, Franke G, Schipper J, Klisch J, Altehoefer C, Zerres K, Januszewicz A, Eng C, Smith WM, Munk R, Manz T, Glaesker S, Apel TW, Treier M, Reineke M, Walz MK, Hoang-Vu C, Brauckhoff M, Klein-Franke A, Klose P, Schmidt H, Maier-Woelfle M, Peczkowska M, Szmigielski C, Eng C; Freiburg-Warsaw-Columbus Pheochromocytoma Study Group. Germ-line mutations in nonsyndromic pheochromocytoma. N Engl J Med 2002;346:1459-1466.

35. Shannon JR, Flattem NL, Jordan J, Jacob G, Black BK, Biaggioni I, Blakely RD, Robertson D. Orthostatic intolerance and tachycardia associated with norepinephrinetransporter deficiency. N Engl J Med 342:541-549. 